\title{
Radical reductions
}

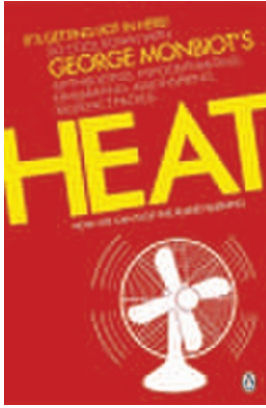

With the recent release of the reports from the Intergovernmental Panel on Climate Change, the science of climate change has become firmer: warming of the climate system is 'unequivocal', and most of the temperature increase since the midtwentieth century is 'very likely' owing to the rise in greenhouse gases. Climate sensitivity - the response of the system to a doubling of $\mathrm{CO}_{2}-$ is now "likely to be in the range 2 to $4.5^{\circ} \mathrm{C}$ with a best estimate of about $3{ }^{\circ} \mathrm{C}$ ". Yet despite the formal coming-into-force of the Kyoto Protocol, the question of what to actually do about climate change in practice remains open. In Heat: How we can stop the planet burning, Monbiot lays out a clear proposition of what we need to do: cut fossil fuel use by about $90 \%$ in the developed world. Most of what follows is an attempt to make this practical, or at least to present options that might be believable, without ending up as "a very poor third world country".

Even so, he is forced to propose changes in society that would cause major upheavals. There is confusion at the heart of this, in that the emissions scenarios that cause us to worry about future warming assume as their basis a world that gets much richer, even allowing for damages from climate change. We could argue (I would) that this is richer in a merely material sense. Nonetheless, people show a considerable appetite for increasing affluence and it is hard to see how large-scale policy changes can be founded against such opposition. To convert such opposition, Monbiot refuses to consider a cost-benefit analysis: to him, it is a moral issue, to be decided on how much we value people and places as such, rather than figures in a ledger. In a popular book aimed at a mass audience this is an attractive approach - we can sweep away all the tedious, difficult and uncertain calculations and simply decide to do what is 'right'. In the real world, this is fraught with difficulties.
The bulk of Heat is a discussion of policies designed to reduce 'our' $\mathrm{CO}_{2}$ emissions down to a sustainable level, to achieve a 'safe' level of climate change. Monbiot settles on $2{ }^{\circ} \mathrm{C}$ above preindustrial temperatures, or $1.4^{\circ} \mathrm{C}$ above present. As it happens, this is also the European Union's target. It is somewhat arbitrary, but for the purposes of exposition a target is needed, and the $2{ }^{\circ} \mathrm{C}$ value is not unreasonable. However, what comes next is unreasonable: Monbiot decides that, if emissions are not lowered from today's values, we are likely to reach this temperature limit by about 2030 . Even with increasing emissions, the IPCC midrange estimates are about $0.3^{\circ} \mathrm{C}$ per decade, giving us an extra 20 years before we hit Monbiot's limit. The confusion gets worse as Monbiot argues that we need a limit of 440 p.p.m.v. of $\mathrm{CO}_{2}$ equivalent to limit temperature rises to $2{ }^{\circ} \mathrm{C}$, and that we are already at this 'safe $\mathrm{CO}_{2}$ ' limit. He then neglects the extra $\mathrm{CO}_{2}$ we will emit between now and 2030.

Having decided on a 'safe' atmospheric $\mathrm{CO}_{2}$ level not too much different from today's, Monbiot is nearly at his goal of finding a 'safe' level of emissions. Taking carbon cycle feedbacks into consideration, he then argues that the biosphere will absorb only 2.7 billion tonnes of carbon per year by 2030, down from 4 billion tonnes now, requiring a $60 \%$ cut in current global $\mathrm{CO}_{2}$ emissions to achieve stability. Carbon cycle feedbacks are a source of great uncertainty; basing all your numbers on one paper from 2003 (C. D. Jones et al. Geophys. Res. Lett. 30, 1479; (2007) neglects this; and yet in a popular exposition some collapsing of uncertainty is required. Finally, by deciding that equity requires everyone

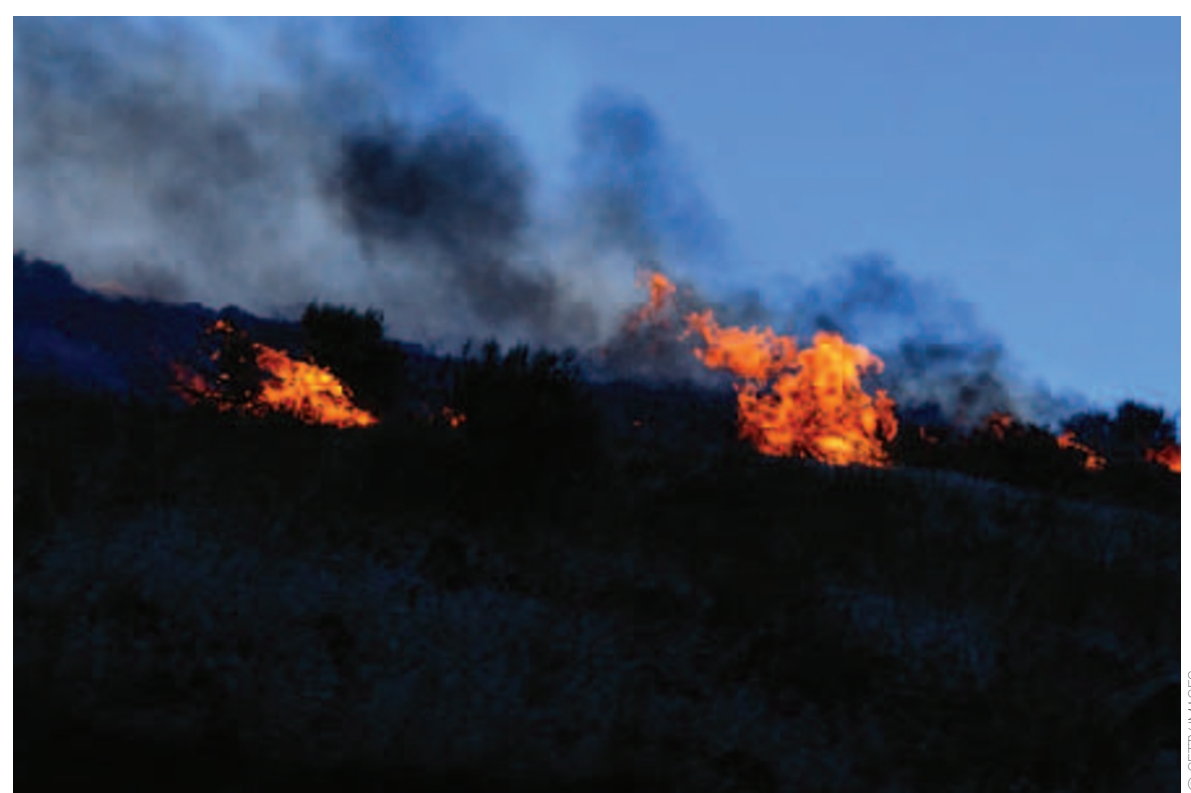

A carbon ration of 0.33 tonnes per person per year is needed to avoid dangerous warming of the planet, says Monbiot. 
to have the same per capita limit, he arrives at a carbon ration of 0.33 tonnes per person per year, a cut of $90 \%$ for an average UK citizen. The last is a big step. By framing it in terms of equity, Monbiot avoids having to spend much effort justifying it, arguing that countries may not like it, but they cannot deny that it is even handed. This seems unlikely to provide a killer argument at international negotiations.

Given all the uncertainties involved, and big practical political obstacles to overcome, Heat is perhaps best regarded as a 'what if': if we did decide to cut greenhouse gas emissions by $90 \%$ within 30 years, what options are available to us to do this? This constitutes the main part of the book, and is a sweep through a large fraction of the carbon emissions of our society, as Monbiot boldly attempts to identify $90 \%$ savings in each area, starting with housing. This proves problematic: although new houses can be built to be far more energy efficient, the low turnover of housing stock precludes any great savings by 2030, and he concludes that only $30 \%$ cuts are possible. This leads to the energy supply industry, where the first option is carbon capture and storage (CCS): continuing to burn fossil fuels as normal, but burying the resultant $\mathrm{CO}^{2}$ perhaps in old oil or gas reservoirs, with the advantage of helping extract a little more fuel in the process. Many environmentalists dislike CCS, as for them the whole point is to use less energy, but Monbiot surprised me by judging it favourably. He concludes that CCS could supply half our electricity by 2030 , which seems optimistic as the International Energy Agency judges it will only start to become usable by 2030 . Nuclear power he considers with trepidation and dismisses. The prescriptions for these sectors are relatively uncontroversial, requiring few changes to behaviour. His prescriptions for transport are more radical: a complete re-vamp with a switch to hypercars, lower speeds and standards of performance, car-free shopping and a major expansion of the bus network. Even this is mild in comparison to the fate of most airplane journeys, which cannot be done within the $\mathrm{CO}_{2}$ budget he imposes.

How does the book fare overall? Monbiot manages, with a degree of optimism, to find probably technologically feasible solutions to most of our $\mathrm{CO}_{2}$ emissions. Where he is far less convincing - especially measured against the recent past and current situation - is in making these changes seem politically feasible.

William Connolley is a climate modeller at the British Antarctic Survey, Cambridge, UK.

\title{
Art from the Arctic
}

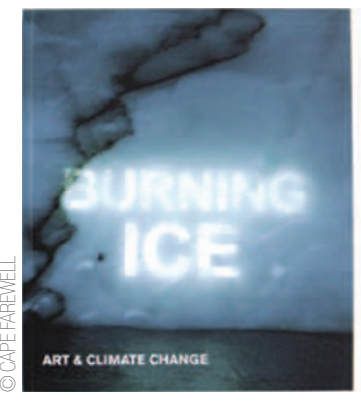

Michael T. Bravo

\section{How central is imagination to our understanding of climate change?}

BURNING ICE: ART AND CLIMATE CHANGE

\author{
Edited by David Buckland, Ali MacGilp, Sion Parkinson
}

Cape Farewell: 2006, 176pp. $£ 19.99$

The Arctic is a difficult space for artists and writers to work in because it is dominated by aesthetic codes from the past. Victorian exploration bequeathed a visual language of melancholic snowy vistas punctuated by sublime icescapes. Twentieth-century makers of natural history documentaries populated these landscapes with closeup images of fauna. Bringing together these two traditions has created the visual language of Arctic natural history as we know it today: the pulse of life dwarfed by a hauntingly harsh and beautiful environment. Yet, the 'pristine Arctic' is largely mythical - the Arctic today is in fact an increasingly desecrated and vulnerable set of linked human landscapes and populated ecosystems. With only slight modification, however, the visual language of the myth is a simple way to communicate a central image for climate change - that of a fragile nature at risk as a result of forces that operate on a global scale. Indeed, it could be argued that climate-change metaphors used to describe the Arctic, such as 'early warning system' or 'canary in the mine', are sufficiently powerful and entrenched in popular communication to obviate the need for assistance from art. Why then organize a group of artists and writers who are mostly unfamiliar with the Arctic to make observations and installations in Svalbard, an archipelago in Norway, with a very beautiful landscape that lends itself to the stereotype of an uninhabited wilderness? Because facts alone do not dispel popular myths like that of the pristine Arctic, and information about such landscapes needs to be communicated using new kinds of images to connect them to public audiences in more meaningful ways.

Inspired to seek a "different way of communicating" climate change, artist David Buckland launched the Cape Farewell Project. Over the course of three expeditions between 2004 and 2006, teams of 20 artists, writers, teachers and journalists (plus the ship's crew) sought to communicate their experience of climate change in the Arctic through unique visual and written representations. Burning Ice: Art and Climate Change brings together the catalogue of artworks and installations that followed the Cape Farewell expeditions alongside essays from scientists, writers and leading climate advisers.

Buckland's initial concept was to sail to Cape Farewell, which is on the southern tip of Greenland, but the opportunity for the expedition's oceanographers to make a transect of the Gulf Stream along the 79th parallel of latitude made Svalbard a more logical destination. Here, the current's most northerly branch was tracked down, dipping silently 30 metres beneath the less-saline water on the stormy surface. The archipelago has, for centuries, offered mariners shelter from the tempestuous seas. As an international site for scientific research under the watchful eye of the Norwegian government, it offered an excellent range of 
locations for writers and artists to make safe excursions, notwithstanding the increasing population of hungry polar bears. Artist Rachel Whiteread described her impulse for walking and listening, to concentrate on "the sound and feel of one's footsteps" and to search for "signs of life... [including] of course the very noisy homo sapiens on their skidoos."

Burning Ice juxtaposes science and art, images and essays, and relations of substance and absence, in imaginative ways. Artists Heather Ackroyd and Dan Harvey tried to see if a lens sculpted out of ice could melt snow or light paper - it didn't, but they did succeed in making a simple camera out of a slice of ice that inverts the landscape. Peter Clegg and Antony Gormley discovered that a pair of monolithic blocks, one erected from blocks of snow, and the other carved out horizontally in the snow, produces contrasting feelings of life and death, an exploration into the "absolutes of Euclidean geometry" in an "un-inscribed Arctic environment". This follows an essay and drawing of a model village designed for decentralized energy production by Charlie Kronick, Chief Policy Advisor of Greenpeace, and precedes David Buckland's slides of 'Collodion on Black Glass'.

Svalbard is a landscape of ghosts. Awaking to the wonders of calving glaciers, it is easy to forget it has long been a geopolitical theatre. In the seventeenth century, Europeans seasonally populated its shores in the thousands in pursuit of oil from bowhead whales, with the result that stocks were decimated. In the twentieth century the presence of energy sources once again makes Arctic territory highly coveted. On the Cape Farewell expedition, artist Alex Hartley draws attention to the politics of sovereignty by laying claim to a new, albeit tiny, island recently exposed by the retreat of a melting glacier, and then names it after himself. Hartley's installation comprising his maps, photographs and correspondence with the Norwegian government authority responsible for approving registering claims, who are seemingly unamused at his attempts to claim that what is to them an "unidentified mineral/rock", is a work of art - an accumulation of heterogeneous ingredients to build a political claim. As for the purpose of Hartley Island, "nothing has yet been ruled out; annexation, independence, tax haven, wildlife sanctuary, short-let holiday homes or time shares". This is an inspired experiment in inviting audiences to reflect on how even the most unappealing Arctic rock is part of a human environment whose legal and political existence has for centuries been hotly contested.
The expedition's work continues when the teams return to Britain. The teams grow as other curators, producers and sponsors enable the writers' and artists' shipboard records to become a "coherent and powerful image capable of conveying those ideas to a wide public". Whereas the opportunities for scientists to convey the personal richness of their field experiences are often limited by professional conventions, collaborations between artists and scientists seem to license much more public and fluid accounts of re-imagining human landscapes. This may help to explain why Cape Farewell has succeeded in gaining acceptance for new climatechange modules in UK Geography and Science school curricula, and why the project continues, with another Arctic expedition scheduled for this coming September. So, too, in seeking greater public scientific literacy, we should take seriously Greg Hilty's advice that "the kind of collaborative research and imagemaking represented by Cape Farewell should surely be the norm rather than the exception".

Michael T. Bravo is the Head of Circumpolar History and Public Policy Research Group Scott Polar Research Institute University of Cambridge, UK e-mail:mb124@cam.ac.auk

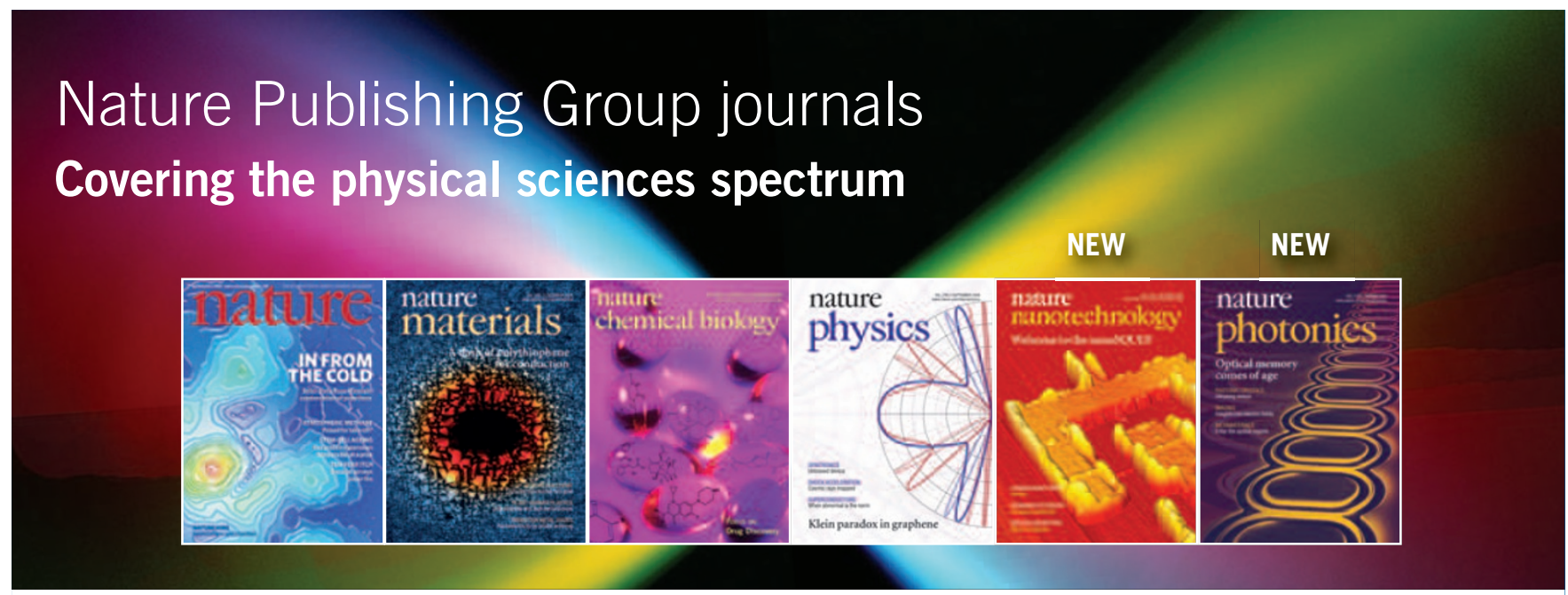

Nature Publishing Group offers a range of journals in the physical sciences - from the broad scope of Nature to specific titles in physics, materials and chemical biology, and new titles in nanotechnology and photonics.

Each journal carries a mix of research papers, review titles, news and views, and commentaries, that will keep you up-todate with the latest research in your area.

Nature Publishing Group's physical science journals are available through personal subscription, institutional print subscription, and site licences. Visit www.nature.com to subscribe today. 